\title{
A PARTICIPAÇÃO DA MULHER DO CAMPO NO CRESCIMENTO DA RENDA FAMILIAR NO NORDESTE BAIANO
}

\section{ARTIGO ORIGINAL}

CRUZ, Delzuita Santana ${ }^{1}$

MOREIRA, Jailma dos Santos Pedreira ${ }^{2}$

CRUZ, Delzuita Santana. MOREIRA, Jailma dos Santos Pedreira. A participação da mulher do campo no crescimento da renda familiar no nordeste baiano. Revista Científica Multidisciplinar Núcleo do Conhecimento. Ano 05, Ed. 10, Vol. 11, pp. 95103. Outubro de 2020. ISSN: 2448-0959, Link de acesso: https://www.nucleodoconhecimento.com.br/educacao/mulher-do-campo

\section{RESUMO}

A realização desse trabalho configura-se do movimento das mulheres no campo e trata-se de uma demonstração da cultura que contribui, cada vez mais, para o crescimento da economia das famílias não só da zona rural, como também da zona urbana. Mostra a legitimidade de um modo de produção pouco reconhecida no meio rural que visa à queda de paradigmas e referenciais sobre a sua própria existência. Este artigo tem como principal objetivo demonstrar a importância da mulher na realização das atividades que garantem o sustento de famílias e de todos aqueles que dependem direta ou indiretamente dessa produção, bem como uma autonomia identitária dentro dos próprios membros e seus modos de vida. Autodenominam-se "mulheres lutadoras do campo". Tais mulheres travam lutas em busca de identidades

\footnotetext{
${ }^{1}$ Mestrado em Ciências da Educação e Multidisciplinaridades; Especialista em Ensino de Língua Portuguesa; Graduada em Letras e Pedagogia.

${ }^{2}$ Orientadora. Doutorado em Letras e Linguística. Mestrado em Letras e Linguística. Especialização em Estudos Literários. Especialização em Texto e Gramática. Graduação em Letras Vernáculas.
} 
autônomas e de construir suas subjetividades, enfrentando preconceitos e descriminações sociais nos espaços públicos os quais ocupam. Este trabalho foi realizado no ano de 2020, através de uma pesquisa exploratória, por meio de formulários com questionários como instrumento investigativo aplicado a 50 mulheres que trabalham na agricultura sendo, portanto, possível perceber que, não só as mulheres (mães) como suas filhas contribuem na produção das atividades no campo. São jovens com idade aproximada entre 10 e 15 anos. Portanto, é necessária uma reflexão sobre os modos de produção das comunidades femininas, diretamente voltadas para a vida das mulheres do campo em buscas do crescimento da renda familiar, unindo força para combater ao preconceito e mudar os padrões impostos pela sociedade machista, e garantir o reconhecimento de igualdade social e liberdade para construir seu próprio meio de vida.

Palavras-chave: mulher do campo, cultura, produção, modos de produção.

\section{INTRODUÇÃO}

No panorama das manifestações culturais e sociais, ao tempo em que se trata de uma realidade cultural vivida por mulheres do campo no nordeste baiano, a Lei no 5.889 , de 8 de junho de 1973, no Art. 3ำ - diz que "Considera- se empregador rural, para os efeitos desta Lei, a pessoa física ou jurídica, proprietário ou não, que explore atividade agro econômica, em caráter permanente ou temporário, diretamente ou através de prepostos e com auxílio de empregados", pensando assim, por possuírem suas próprias atividades que resultam na criatividade e autonomia de indivíduos pertencentes a um meio de vida própria, o que se espera é que essas mulheres sejam reconhecidas no meio social em que estão inseridas e tenham igualdade mediante a sua produtividade, garantindo políticas públicas de inserção no mercado de trabalho. O que se verifica, porém, são ações com o objetivo de limitar ou impedir a avanço feminino no reconhecimento do livre exercício na sua produção por parte até mesmo dos seus companheiros, bem como descriminação do seu modo de vida pela sociedade machista. 
Esta pesquisa mostra a legitimidade de um modo de produção pouco reconhecido no meio rural que visa à queda de paradigmas e referenciais sobre a sua própria existência. Preocupadas em produzir de forma autônoma e conseguir o seu espaço social, essas mulheres se reúnem sempre procurando mostrar a necessidade de construir o seu próprio negócio e de maneira conceituada. Nesse designío, torna-se necessária pensar numa metodologia na tentativa de chegar à conclusão através dos relatos de como se dá o comportamento e os modos de produção dessas pessoas que se autodenominam como "Mulheres lutadoras do campo". Para tanto, ao modo em que este se configura como um momento discursivo, consequentemente situado no campo da atuação desses sujeitos, bem como uma atitude de acepção que podem proporcionar diversas interpretações diferentes. Essa análise surge a partir dos modos de produção dos sentidos de vida diante de uma cultura que está embasado na concepção de sujeito daquelas pessoas e do que elas almejam alcançar. Com base em dados

\section{MODOS DE VIDA DAS MULHERES COMO SUJEITO SOCIAL NA PRODUÇÃO DO TRABALHO NO CAMPO}

O trabalho e a participação da mulher do campo como sujeito social traz uma reflexão com relação às lutas travadas em busca da construção da sua história e na conquista pelo seu espaço. $O$ intuito é promover uma reflexão sobre as mulheres como autores relevantes na combinação para o avanço da vida no campo. Essas mulheres buscam novos sentidos emergenciais sobre as suas reivindicações, principalmente pelo direito à propriedade da terra e à participação direta na agricultura local e ou regional.

Durante a realização dessa pesquisa foi possível perceber que, não só as mulheres (mães) como suas filhas contribuem com as atividades na produção do trabalho no campo. Essas jovens têm entre 10 e 15 anos de idade. Algumas contribuem carregando água para abastecer as pequenas cisternas, bem como cuidando dos afazeres domésticos e da alimentação dos irmãos mais novos. Outras participam diretamente das atividades na roça como arar as terras, o plantio e a colheita. Podemos considerar que essas jovens, desde a infância, já contribuem com a renda 
familiar, inclusive buscando conciliar com os estudos. Essas meninas, desde cedo, lutam para serem respeitadas como trabalhadoras rurais e inseridas no meio social como protagonistas da sua própria existência. Essa é uma realidade que necessita de uma luta mais extensa.

Diante dos estudos, ao refletir sobre os modos de produção das camponesas do nordeste baiano, é necessário observar o local onde acontece esse cenário, qual é o seu destino, e se está surtindo efeito sobre as propostas que estão sendo apresentadas, pois segundo Mcdowell (2000):

Os espaços surgem das relações de poder; as relações de poder estabelecem as normas; e as normas definem os limites, que são tanto sociais como espaciais, porque determinam quem pertence a um lugar e quem é/será excluído, assim como a situação local de uma determinada experiência (MCDOWELL, 2000, p. 19).

Com base na afirmação do autor, compreende-se que é nessa relação entre sujeitoespaço que elas se encontram no que se refere ao campo das discussões sociais através da compreensão nos momentos conflituosos que impactam nas decisões do cotidiano, até porque se observa nesse espaço apontado para mulheres, que elas não se distanciam umas das outras, dialogam constantemente em busca de políticas que aproximem-nas da economia e do trabalho, transformando esses ambientes em espaços reais, bem próximo do cotidiano, uma vez que tanto a economia doméstica quanto a solidária são bastante discutidas nos movimentos sociais. Essa é uma prática cultural que, para que haja avanço no comportamento das pessoas nesse contexto, requer luta, persistência e determinação. São práticas culturais que, segundo Raymond Williams (2000) não descende somente de uma regra social diferentemente formada, mas são também elementos imprescindíveis em sua constituição. Compreendemos, portanto, que a cultura inspira o crescimento da sociedade, estreitando os laços com a política econômica, na tentativa de analisar paralelamente em meio aos fatores sociais. Assim, o significado dessa cultura se executa com base na transformação do sujeito, e com o significado em que hábitos são aplicados no meio social em que essas mulheres estão inseridas, reinventado, estruturando e analisando por diversas esferas sociais. 
Ao analisar os escritos de Culler (1999), no que diz respeito à cultura, é possível compreender que essa tem relação direta com os modos de produção dessas pessoas a partir do modo de vida de cada uma. É possível ainda que, à medida que essa prática se estabeleça entre elas cresçam as possibilidades de alcançar a valorização no meio social. Segundo o autor, os estudos culturais se manifestam e ganham espaço pela vontade de representar a cultura popular ou dar autonomia nas expressões culturais, que nesse cenário, está representado através da mulher do campo.

\section{A ORGANIZAÇÃO DA MULHER NO TRABALHO DO CAMPO}

"Mulher lutadora do Campo" refere-se à maneira que eles se constituem enquanto pessoas que assim se percebem dentro de um cenário que, por sua vez, não são compreendidas como sujeitos donos dos seus próprios meios de vida. Essa noção parte de suportes que são extraídos da própria luta pela existência em busca de caracterizar o comportamento, a organização das ações no campo em busca do crescimento e valorização do trabalho de cada uma. Isso se dá através dos relatos, documentários, e até mesmo de fotografias registradas durante a atuação do trabalho.

Se levarmos em consideração a luta dessas mulheres em busca de espaço de representatividade, mediante à sociedade local, já representa uma vitória significativa para boa parte dessa classe lutadora, uma vez eu os projetos apresentados aos representantes de sindicatos já têm sido, ao menos, analisados. Esse é um fator considerado importante para o crescimento e fortalecimento dessas pessoas, de modo que vão surgindo novas maneiras de enfrentamento para amenizar as batalhas do cotidiano. A busca pelo apoio da "Associação dos Pequenos Agricultores do Estado da Bahia" (APAEB). A APAEB451 (MOC) tem sido uma das inquietações dessa gente. A ideia é tornar visível a presença da mulher em busca de liberdade econômica.

Nos relatos aqui manifestados procuramos verificar os discursos apresentados sobre as pessoas que procuram um lugar no espaço em que estão inseridas, no que diz respeito à organização e adequação. Dessa forma, essa pesquisa tomou como base, também, as hipóteses apresentadas por Foucault, na obra $A$ ordem do discurso 
(1996), que relata que todo discurso é decorrente de um contexto histórico, cultural, político e científico, com as suas particularidades de acordo com o tempo e que devem ser levadas em consideração mediante os estudos realizados, uma vez que os "discursos religiosos, judiciários, terapêuticos e, em parte também, políticos, não podem ser dissociados dessa prática de um ritual que determina para os sujeitos que falam, ao mesmo tempo, propriedades singulares e papéis preestabelecidos". (FOUCAULT, 1996, p.37). Dessa forma, podemos perceber que a luta diária da "mulher trabalhadora do campo" se manifesta por meio de ações e de discussões em busca de um lugar no espaço em que estão inseridas.

Foucault (1996) relata:

não é simplesmente aquilo que manifesta (ou o oculta) o desejo; é também, aquilo que é o objeto do desejo; e visto que - isto a história não cessa de nos ensinar - o discurso não simplesmente aquilo que traduz as lutas ou os sistemas de dominação, mas aquilo porque, pelo que se luta, o poder do qual nos queremos apoderar. (FOUCAULT, 1996, p. 10).

Desse modo, os discursos proferidos por essas camponesas potencializam a luta pela conquista na produção de representatividade que busca fortalecer a produtividade no que tange a renda familiar mediada por mulheres, descontruindo uma história que está enraizada na humanidade, por séculos e séculos. Fica claro, então, o entendimento de que o "discurso como um objeto cultural, produzido a partir de certas condicionantes históricas". (FOUCAULT, 1996, p. 37) é imprescindível para vencer e alcançar suas conquistas.

Podemos nos basear nas teorias de Fredric Jameson (1996), que na pósmodernidade encontra-se a lógica cultural do capitalismo tardio. Para ele a cultura tem influência direta na economia. Ao dissertar uma ideia histórica da pós-modernidade, o teórico aponta a importância da crítica cultural no cenário econômico, da mesma forma em que é necessário pensar em políticas educativas que visem tornar os sujeitos independentes em uma escala global. A crítica do autor diz respeito, especialmente, às práticas sociais que relacionam a cultura como algo que segue ideologias do capitalismo. Assim, diante dos relatos de Jameson, nota-se que o modo de vida das mulheres do campo busca uma liberdade que aos poucos vem sendo conquistada, $e$ 
que, mesmo marcada pelo preconceito, discriminação de gênero, desrespeito pela classe feminina e trabalhadora, vale a pena lutar com estratégias de enfrentamento em busca de um ideal que represente uma coletividade.

\section{CONSIDERAÇÕES}

As discussões fortalecidas durante essa pesquisa permeiam as relações sociais entre mulheres e o meio social. Elas destacam sobre essas relações sociais os conceitos e a cultura a partir modos de vida, e de um ponto de vista histórico constituído pelos sujeitos de quem compõem uma sociedade. Dessa forma, as práticas realizadas em prol da construção coletiva do modo de produção vivenciado em um espaço social, assumem a definição que constitui um determinado sujeito.

Conclui-se, portanto, que é necessário um olhar crítico sobre a análise dos modos de produção das comunidades femininas, especialmente vivenciada por mulheres do campo em buscas de alternativas que as aproxime dos objetivos almejados e que sejam capazes de mostrar o seu potencial enquanto sujeito de uma sociedade que contribui diretamente com o crescimento da renda familiar de fortalecer a economia da região em que estão inseridas. Assim, estabelecer força de combate ao preconceito e mudar os padrões impostos pela sociedade machista, surgindo novas possibilidades, na maneira de agir em busca de alternativas de igualdade social e liberdade para construir seu próprio meio de vida.

Desse modo, esses debates referentes à busca pela valorização da mulher do campo e a sua participação no crescimento da renda familiar, não será o suficiente para findar a busca pelas práticas e lutas que movem em busca por transformações do espaço e do tempo, bem como seus impactos no contexto dos modos de produção das mulheres do campo. Sendo assim, essa pesquisa busca mostrar a luta de mulheres do campo em conquistar e se apresentar diante do seu mundo, acentuando a necessidade de tornar distantes as imposições conceituais para compreender a legitimidade do seu universo cultural. Segundo Scott (1989), a inserção das mulheres na história demanda um crescimento que faz parte de um cenário histórico importante para a construção de uma nova história da mulher. 
A presença das mulheres nas lutas sociais no campo configura-se parte de nossa história e com o surgimento de várias lideranças. O que parece ser novidade nesse processo de igualdade das classes sociais é a emergência em atender as reivindicações dessas mulheres. O reconhecimento social da real condição de trabalhadoras rurais, uma luta constante por uma identidade que expresse o direito à sindicalização, até mesmo sobre a chance de adquirir suas terras e tocar seu próprio negócio.

\section{REFERÊNCIAS}

CULLER, Jonathan. Teoria Literária: uma introdução. São Paulo: Beca Produções Culturais Ltda., 1999.

FOUCAULT, Michel. A ordem do discurso: aula inaugural no Collège de France, pronunciada em 2 de dezembro de 1970. Tradução de Laura Fraga de Almeida Sampaio. São Paulo: Edições Loyola, 2012.

GIBSON, Tânia Maria de Jesus. O MOC: Movimento de conscientização política durante a ditadura militar brasileira na cidade de Feira de Santana-BA (1964-1979). Natal, 2005. (Monografia). Universidade Federal Do Rio Grande Do Norte Centro De Ciências Humanas, Letras E Artes Departamento De História.

JAMESON, Fredric. Pós-modernidade: a lógica cultural do capitalismo tardio. São Paulo: Ed. Ática, 1996.

LEI № 5.889, DE 8 DE JUNHO DE 1973. D.O.U. de 11.6.1973

MCDOWELL, Linda. Gênero, identidad y lugar: un estudio de las geografías feministas. Valencia: Cátedra, 2000: a lógica cultural do capitalismo tardio. São Paulo: Ed. Ática, 1996.

PARISSE, Tândja Andréa. A sociedade civil no contexto da Ditadura: experiência do Movimento de Organização Comunitária (MOC, na região de Feira de Santana no 
período de 1968 a 1979). Feira de Santana: UEFS, 2001. Monografia de Especialização em Teoria e Metodologia da História.

SCOTT, Joan W. Gênero, uma categoria útil de análise histórica. Educação e Realidade. Porto Alegre: Faculdade de Educação/UFRGS, Vol.6, № 2, jul/dez, 1989.

WILLIAMS, Raymond. Cultura. 2.ed. São Paulo: Paz e Terra, 2000.

Enviado: Julho, 2020.

Aprovado: Outubro, 2020. 